GAPP, número 23, mayo-octubre de 2020

Sección: EXPERIENCIAS Y CASOS

Recibido: 27-11-2019

Modificado: 08-01-2020

Aceptado: 06-02-2020

DOI: 10.24965/gapp.i23.10754

Páginas: 152-166

\title{
Eficacia de las medidas políticas e índices internacionales de criminalidad: el caso de la República del Ecuador
}

\section{Effectiveness of political measures and international crime rates: The case of the Republic of Ecuador}

\author{
Jose Luis Vilchez Tornero \\ Universidad de Granada (España) \\ ORCID: https://orcid.org/0000-0001-5288-8791 \\ jlvil@hotmail.de
}

\section{NOTA BIOGRÁFICA}

PhD en Psicología experimental y Neurociencia del Comportamiento, Máster en Neurociencia cognitiva y del Comportamiento y Licenciado en Psicología. Actualmente es Profesor Titular de Universidad e imparte las asignaturas de Psicología del Aprendizaje, Historia de la Psicología y Psicología fisiológica.

Román Mauricio Buñay Andrade

Empresa Eléctrica de Limón (Ecuador)

ORCID: https://orcid.org/0000-0002-4947-1001

romanbunay@gmail.com

\section{NOTA BIOGRÁFICA}

Máster en Energías renovables y Licenciado en Ingeniería eléctrica. Docente universitario y Administrador de la Empresa Eléctrica de Limón.

\section{RESUMEN}

En la actualidad, se carece de índices científicos y fidedignos que muestren la eficiencia de los actuales gobiernos. Estos índices son los que deberían guiar nuestras actitudes y conductas de participación política, en lugar de las referencias vagas y los procesos cognitivos incompletos que lo hacen actualmente. El presente trabajo significa la puesta en marcha de una iniciativa más global de análisis científico de la política. Se ha llevado a cabo un análisis de índices de criminalidad a lo largo del tiempo y precisando la instauración de medidas políticas que ayudan a explicar las variaciones de dichos índices. El diseño de estudio es cuasi-experimental (con comparación de los susodichos índices a lo largo de los años) y correlacional (de dichos índices con índices de riqueza, desigualdad o criminalidad internacional, entre otros). En el caso de la República del Ecuador y para los índices de criminalidad estudiados, se puede afirmar que las medidas políticas del gobierno durante el periodo 2010-2016 fueron efectivas. 
GAPP. Nueva Época - N. 23, mayo-octubre 2020 - ISSN: 1989-8991 - DOI: 10.24965/gapp.i23.10754 - [Págs. 152-166]

Eficacia de las medidas políticas e índices internacionales de criminalidad: el caso de la República del Ecuador Jose Luis Vilchez Tornero / Román Mauricio Buñay Andrade

\title{
PALABRAS CLAVE
}

Eficiencia política; actores sociales; ciudadanía; medidas políticas; participación política.

\begin{abstract}
Nowadays, scientific and reliable indexes are lacking for showing the efficiency of current governments. These indexes should guide our attitudes and behaviors of political participation, instead of the vague references and the incomplete cognitive processes that currently do it. The present work means the implementation of a more global initiative of scientific analysis of political measures. An analysis of crime indices has been carried out over time. It has been taken into account the application of political measures, which helps to explain the variations of these indices. The study design is quasi-experimental (with comparison of the aforementioned indices over the years) and correlational (of these indices with indices of wealth, inequality or international crime, among others). In the case of the Republic of Ecuador and for the crime rates studied, it can be affirmed that the government's policy measures during the period 20102016 were effective.
\end{abstract}

\section{KEYWORDS}

Political efficiency; social actors; citizenship; political measures; political participation.

\section{SUMARIO}

1. MÉTODO. 1.1. PARTICIPANTES. 1.2. MATERIALES Y PROCEDIMIENTO. 1.3. DISEÑO. 1.4. ANÁLISIS DE DATOS. 2. RESULTADOS. 2.1. HOMICIDIOS. 2.2. VIOLACIONES. 2.3. ROBOS EN GENERAL. 3. CONCLUSIONES. REFERENCIAS BIBLIOGRÁFICAS.

Las representaciones sociales acerca de fenómenos sociales son formas de conocimiento que condicionan a la sociedad y a su actividad mental (Moscovici, 1984). Estas representaciones mentales, guían las actitudes y, por tanto, los comportamientos sociales, formando el campo psicológico de referencia en el que se evalúan las acciones sociales (Galam y Moscovici, 1991). Los sistemas políticos no disponen en la actualidad de forma sistematizada de extensas bases de datos con índices no sólo económicos sino sociales, ni de metodologías científicas de recogida y análisis de las acciones políticas que implementan. La finalidad de disponer de estos datos es que puedan ser constatados por cualquier observador/ciudadano. En este sentido, existe una carencia de iniciativas de investigación sobre la eficacia de la toma de decisiones de los gobiernos. Algunos intentos pueden encontrarse en la literatura (e.g., Abascal et al., 2013; Aguilera, 2000; Aguirre Briones, 2009; Bedoya Bedoya, 2015; Blanco Bosco, 2009; Díaz Polanco y Candela, 2014; Lam Díaz y Hernández Ramírez, 2008; Pastor Seller, 2012; Rivera Castillo, Astete, Linares y Huanco, 2005; Rodríguez-Ponce, 2007; Sandín-Vázquez y Sarría-Santamera, 2008; Yopo Díaz, 2012) pero éstos adolecen de un análisis de índices claros y la mayoría se limitan al análisis teórico. Por tanto, la evaluación sobre la eficacia de los sistemas de gobernación adolece de criterios fidedignos que orienten a la ciudadanía en su toma de decisión y participación política. Se postula que un sistema de gobierno tiene más apoyos cuanto más claras sea la representación de su eficacia por parte de los ciudadanos en la solución de problemáticas sociales. En este sentido, las «notas mentales» (en términos de Vilchez, 2016) que los ciudadanos tienen acerca de la eficacia del sistema político serán la base de su actitud y conducta hacia dicho sistema.

En el estudio del fenómeno colectivo, la literatura se ha centrado en los cambios de actitud y la toma de decisiones como proceso cognitivo sin tener en cuenta el material objeto de procesamiento (Galam y Moscovici, 1991). En estos procesos, independientemente del contenido de la información o su validez argumental, se ha observado que el «consenso» y, por tanto, la toma de decisión se sitúa de forma más cercana al extremo polarizado dominante (en términos tanto de número de elementos del grupo como del poder del mismo), más que en el promedio entre los dos polos argumentales opuestos. A este fenómeno se le denomina como «polarización del grupo» (Moscovici y Zavalloni, 1969). 
La base de la argumentación del presente trabajo se halla en el hecho de que los niveles individuales de argumentación pueden cambiar los niveles grupales (Dion, Baron y Miller, 1970). En este sentido, estudios empíricos con jurados simulados han demostrado que un simple individuo puede cambiar la toma de decisiones del grupo entero sin ni siquiera tener datos reales sobre el caso (Davis, Stasson, Ono y Zimmerman, 1988). A este respecto, se encuentra en la literatura que, en condiciones grupales, los sujetos toman decisiones significativamente más arriesgadas que cuando deben hacerlo individualmente (Stoner, 1961). Se postula que los datos científicos deben tener más peso que los datos «imaginarios» en una posible discusión orientada al convencimiento sobre una toma de decisión y que «respalda» las decisiones grupales más arriesgadas que se llevan a cabo. En el caso que nos ocupa, el contexto de decisión grupal es el contexto de decisión política, tanto en los niveles de toma de decisiones gubernamentales como en el nivel de toma de decisión de participación política por parte de los ciudadanos.

Vivimos en la época de proliferación de numerosas asociaciones y comités que deben decidir infinidad de acciones acerca de investigación, salud, medio ambiente o ética. La falta de claridad en los niveles de análisis de la información ha sido propuesta como la causante de la polarización del grupo y la raíz de la problemática de falta de eficacia social (Galam y Moscovici, 1991); lo cual igualmente podría ser aplicado a la administración pública. Independientemente de que ya sea para tomar las decisiones sobre la creación de políticas públicas por parte del gobierno (o los agentes encargados por él) o para evaluar dichas políticas por parte de los ciudadanos, se ha comprobado que cuanto más polarizados están los grupos, mayor aumento de dicha polarización se producirá si se produce una discusión (Myers y Bishop, 1970); lo cual no es dificultoso hoy en día, teniendo en cuenta las nuevas tecnologías de la comunicación y redes sociales (e.g., www.facebook.com).

La motivación de esta investigación es, por tanto y bajo este prisma de utilidad social, proporcionar al ciudadano herramientas de decisión cognitiva para su toma de decisiones. La hipótesis, en consecuencia, es suponer que ciertas medidas políticas que han acaecido en la República del Ecuador han tenido (en principio) efectividad social y han conseguido reducir o aumentar, en su caso, los índices que representan el bienestar social.

\section{MÉTODO}

\subsection{Participantes}

Los participantes de este estudio son todos los ciudadanos ecuatorianos que vivieron durante los años de análisis (2010-2016) en la República del Ecuador en los distintos sectores entre los que se divide el país y en donde se registraron los índices de violaciones, homicidios y robos. Según el Instituto Nacional de Estadística Ecuatoriano ([INEC], 2014), la población en la República del Ecuador para el 2010 giró en torno a los 14.483 .499 de habitantes; distribuidos en los 224 municipios objeto de registro y análisis de este estudio.

\subsection{Materiales y procedimiento}

Durante los años del 2010 al 2016 el Ministerio Coordinador de Seguridad (a través de las sedes locales de la Policía Nacional y Guardia Urbana) registró el número de violaciones, homicidios y robos (a su vez divididos en: (a) robos a domicilios; (b) robos a personas; (c) robos de accesorios a vehículos; (d) robos de motos; (e) robos de vehículos; y (f) robo en unidades monetarias. Evidentemente, de todos los crímenes anteriores cometidos, únicamente se registraron los denunciados (dado que, lógicamente, han existido incidentes que no han sido inscritos porque las personas implicadas no lo han reportado). Estos datos fueron cedidos para su análisis en el presente estudio.

Por otro lado, con el fin de explicar algunas fases de repuntes y bajadas de las tendencias anteriores, se analizó a nivel internacional la relación entre el Producto Interior Bruto (PIB; indicador del desarrollo económico de un país; Banco Mundial, 2017a) y el coeficiente Gini (indicador de la desigualdad en los ingresos dentro de un país; ambos proporcionados por el Banco Mundial, 2017b) y los índices de homicidios, violaciones y robos según la Oficina de las Naciones Unidas contra la Droga y los Crímenes (UNODC, 2015); con el fin de aportar datos que pudieran ayudar a entender ciertos resultados en la tendencia de los datos anteriores. 
En cuanto a la relación del PIB con los índices de criminalidad, los datos proporcionados por ambas entidades (Banco Mundial y UNODC, respectivamente) sólo se cruzan en el año 2001 y 2002 para los 46 países de: Albania, Alemania, Arabia Saudita, Argentina, Austria, Azerbaiyán, Belarús, Bélgica, Bolivia, Canadá, Chipre, Costa Rica, Croacia, Dinamarca, El Salvador, Eslovenia, Estados Unidos, Filipinas, Finlandia, Hungría, Irlanda, Islandia, Italia, Kuwait, Letonia, Lituania, Luxemburgo, Maldivas, Malta, Marruecos, México, Namibia, Nepal, Nueva Zelandia, Omán, Países Bajos, Panamá, Perú, Polonia, República Checa, Rumania, Sudáfrica, Suecia, Suiza, Túnez y Uruguay. Para algunas observaciones, falta algún dato del PIB o de criminalidad para algún país, ya sea para el 2001 o para el 2002. Esto hace que el número de observaciones difiera de análisis en análisis.

Con respecto al cruce del coeficiente Gini con los índices de criminalidad (igualmente proporcionados por el Banco Mundial y la UNODC, respectivamente), los datos igualmente se cruzan en el año 2001 y 2002 sólo para los países: Albania, Argentina, Belarús, Bolivia, Costa Rica, El Salvador, México, Panamá, Perú y Rumania.

\subsection{Diseño}

Diseño cuasi-experimental. Para el análisis de las tendencias en la criminalidad de la República del Ecuador durante los años del 2010 al 2016, el diseño de recogida de datos fue un diseño cuasi-experimental (debido a que los grupos no fueron formados al azar y al número de Variables Extrañas [VEs] que podrían estar igualmente explicando los datos) de medidas repetidas, con 9 Variables Dependientes (VDs) pertenecientes a los índices de registro de: (a) violaciones; (b) homicidios; (c) robos en general; (d) robos a domicilios; (e) robos a personas; (f) robos de accesorios a vehículos; $(\mathrm{g}$ ) robos de motos; (h) robos de vehículos; y (i) robo en unidades monetarias. Se entiende por unidades monetarias aquellos recintos en los que se utiliza efectivo para el comercio de bienes o servicios. Las Variables Independientes (VIs), que el Gobierno de la República del Ecuador manipuló en forma de la introducción de normativas de ámbito nacional durante los años de análisis, fueron: (a) control de armas de fuego (Instructivo para la intervención de los intendentes generales de la policía del país, Ministerio del Interior; Acuerdo Ministerial § 2521, 2009); (b) límite de expendio (o entrega gratuita) de bebidas alcohólicas para establecimientos de diversión (Regulación de venta de bebidas alcohólicas, Ministerio de Turismo; Acuerdo Ministerial § 1470, 2010); y (c) reforma a dicho límite (Acuerdo Ministerial § 1470, 2014).

Diseño correlacional. La relación significativa entre ciertas variables económicas y los índices de criminalidad internacionales se analizó con la correlación entre el PIB y los índices de homicidios cometidos, violaciones registradas y robos registrados. Por otro lado, el coeficiente Gini fue igualmente relacionado con los índices de homicidios cometidos, violaciones registradas y robos registrados.

\subsection{Análisis de datos}

Diseño cuasi-experimental. Dado que ninguna de las VDs de criminalidad tiene unidad de medida (e.g., un robo no puede compararse con otro y tampoco tiene infinitésimos niveles de contabilización entre un extremo del intervalo y otro), son variables discretas y requieren un tratamiento estadístico no-paramétrico. La tendencia de los datos sobre criminalidad durante los años de análisis (2010-2016) fue testada con el estadístico de Friedman. Para las comparaciones entre años consecutivos, teniendo igualmente en cuenta la naturaleza de las variables, se utilizó la prueba no-paramétrica de rangos con signo de Wilcoxon. Con estos dos análisis se pudo analizar tanto la tendencia significativa a través de los años de análisis como la diferencia significativa de forma individual entre años consecutivos.

Diseño correlacional. En este análisis, el PIB fue calculado como el resultado del valor monetario de la producción de bienes y servicios de un país. El índice Gini, por el contrario, fue calculado como la proporción de la curva de Lorenz producto de la diferencia entre la distribución ideal de la riqueza y la distribución real de la misma. La distribución real de la riqueza se expresa por una relación lineal perfecta con pendiente 1 entre la proporción acumulada de los ingresos totales del país (eje y) y la proporción acumulada de la población (eje $x$ ). De igual forma que en análisis anteriores, dada la naturaleza discreta de todos los índices de criminalidad incluidos en este análisis (pese a que las variables del PIB y coeficiente Gini sí son continuas), se realizó una Tau-b de Kendal para corroborar la correlación signi- 
ficativa entre el PIB y el coeficiente Gini, cada uno, con respecto a los índices de homicidios cometidos, violaciones registradas y robos registrados.

\section{RESULTADOS}

\subsection{Homicidios}

El promedio de homicidios en el año 2010, primer año registrado, para la República del Ecuador fue de $11.77(D E=44.80)$, mostrando un descenso en el último año de registro, el año $2016(M=4.22, D E=15.24$; ver Figura 1). Esta reducción fue significativa, $X^{2}(6,222)=94.26, p<.001$, tomando en cuenta las 223 observaciones que representan los cantones (municipios) o ciudades en los cuales los datos fueron registrados; durante los siete años en los que se centró el análisis (2010-2016).

\section{Figura 1. Media de homicidios Cometidos en los 223 municipios de LA República del EcuAdor DURANTE EL PERIODO 2010-2016}

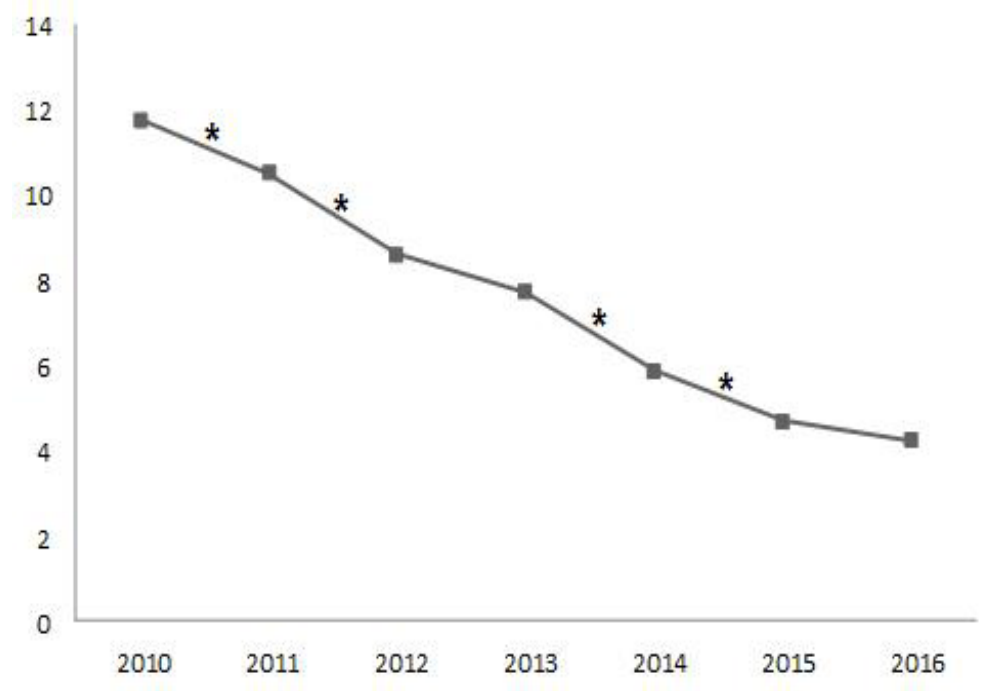

Fuente: Elaboración propia.

Se realizó una comparación por pares de años, con el fin de analizar cada uno de los intervalos temporales anuales. En este sentido, se desvelan decrementos significativos entre: (a) los años 2010 ( $M=11.77$, $D E=44.80)$ y $2011(M=10.51, D E=37.83), Z(223)=2, p<.046, r=.134 ; \mathrm{y}(\mathrm{b})$ los años $2011(M=10.51, D E$ $=37.83)$ y $2012(M=8.62, D E=29.38), Z(223)=3.23, p<.002, r=.216$ (ver Tabla 1 y Figura 1$)$. En cambio, durante el 2012, los datos se estabilizan, perdiendo significatividad estadística el decremento inicial. Este primer descenso está relacionado con el traslado del control de armas de fuego (inicialmente a cargo de las Fuerzas Armadas) a la Policía Nacional; de acuerdo a los Ministerios de Defensa y Ministerio de Gobierno de la República del Ecuador (Acuerdo Interministerial $\S 1502,2009$ ) que fue implementado durante el año 2009. Este acuerdo interinstitucional recalifica los permisos de tenencia y porte de armas, lo que implica un levantamiento de información detallada tanto de las armas en sí como de sus propietarios. Igualmente, en el descenso en los homicidios influyó la medida de límite en el expendio de bebidas alcohólicas (Acuerdo Ministerial $\S 1470,2010)$ en su primera versión para el 2010. Existe otro nuevo descenso significativo entre: (a) el año $2013(M=7.74, D E=28.13)$ y $2014(M=5.87, D E=19.94), Z(223)=3.54, p<.001, r=.237$; y (b) el año $2014(M=5.87, D E=19.94)$ y $2015(M=4.70, D E=17.38), Z(223)=3.97, p<.001, r=.266$ (ver Figura 1). En los años 2015 y 2016 los datos vuelven a estabilizarse. El nuevo repunte descendente que comienza en el año 2014 está motivado por la reforma de la medida del límite de expendio (o entrega gratuita) de bebidas alcohólicas para establecimientos de diversión (Acuerdo Ministerial § 1470, 2014) que fue instaurado en ese preciso año. 
GAPP. Nueva Época - N. 23, mayo-octubre 2020 - ISSN: 1989-8991 - DOI: 10.24965/gapp.i23.10754 - [Págs. 152-166]

Eficacia de las medidas políticas e índices internacionales de criminalidad: el caso de la República del Ecuador Jose Luis Vilchez Tornero / Román Mauricio Buñay Andrade

TABLA 1. ANÁlisis Wilcoxon POR PARES de AÑos PARA EL PERIOdo 2010-2016

\begin{tabular}{|c|c|c|c|c|c|c|c|c|c|c|c|c|c|c|c|c|c|}
\hline & \multicolumn{3}{|c|}{ 2010-2011 } & \multicolumn{3}{|c|}{ 2011-2012 } & \multicolumn{3}{|c|}{ 2012-2013 } & \multicolumn{3}{|c|}{ 2013-2014 } & \multicolumn{3}{|c|}{ 2014-2015 } & \multicolumn{2}{|c|}{ 2015-2016 } \\
\hline & $\begin{array}{c}Z \\
(1,223)\end{array}$ & $p$ & $r$ & $\begin{array}{c}Z \\
(1,223)\end{array}$ & $p$ & $r$ & $\begin{array}{c}Z \\
(1,223)\end{array}$ & $p$ & $r$ & $\begin{array}{c}Z \\
(1,223)\end{array}$ & $p$ & $r$ & $\begin{array}{c}Z \\
(1,223)\end{array}$ & $p$ & $r$ & $\begin{array}{c}Z \\
(1,223)\end{array}$ & $p$ \\
\hline Homicidios & 2,00 & $<.046^{*}$ & .134 & 3,23 & $<.002^{*}$ & .216 & 1,64 & $=.103$ & .110 & 3,54 & $<.001^{*}$ & .237 & 3,97 & $<.001^{*}$ & .266 & 1,81 & $=.071 .121$ \\
\hline Violaciones & 3,03 & $<.003^{*}$ & .203 & 7,10 & $<.001^{*}$ & .476 & 1,99 & $<.048^{*}$ & .133 & 1,60 & $=.111^{*}$ & .107 & 2,12 & $<.035^{*}$ & .142 & 1,90 & $=.059 .127$ \\
\hline Robo en general & 10,06 & $<.001^{*}$ & .673 & 8,72 & $<.001^{*}$ & .584 & 3,57 & $<.001^{*}$ & .239 & 0,58 & $>.250$ & .039 & 2,42 & $<.017^{*}$ & .162 & 8,39 & $<.001 .562$ \\
\hline Robo a domicilios & 5,66 & $<.001^{*}$ & .379 & 6,16 & $<.001^{*}$ & .413 & 2,90 & $<.005^{*}$ & .194 & 5,94 & $<.001^{*}$ & .398 & 4,65 & $<.001^{*}$ & .311 & 5,83 & $<.001^{*} .390$ \\
\hline Robo a personas & 5,13 & $<.001^{*}$ & .344 & 4,16 & $<.001^{*}$ & .279 & 1,59 & $=.113$ & .106 & 3,41 & $<.002^{*}$ & .228 & 2,29 & $<.023^{*}$ & .154 & 2,59 & $<.011^{*} .173$ \\
\hline $\begin{array}{l}\text { Robo de accesorios } \\
\text { de vehículos }\end{array}$ & 2,92 & $<.005^{\star}$ & .195 & 4,76 & $<.001^{*}$ & .319 & 3,26 & $<.002^{*}$ & .218 & 7,11 & $<.001^{*}$ & .476 & 0,84 & $>.250$ & .056 & 5,13 & $<.001 * .343$ \\
\hline Robo de motos & 4,09 & $<.001^{*}$ & .274 & 0,05 & $>.250$ & .004 & 2,22 & $<.027^{*}$ & .149 & 0,54 & $>.250$ & .036 & 0,11 & $>.250$ & .008 & 1,80 & $=.073 .120$ \\
\hline Robo de vehículos & 1,86 & $=.064$ & .125 & 5,26 & $<.001^{*}$ & .353 & 0,83 & $>.250$ & .055 & 5,56 & $<.001^{*}$ & .372 & 3,73 & $<.001^{*}$ & .250 & 0,73 & $>.250 \quad .049$ \\
\hline $\begin{array}{l}\text { Robo a unidades } \\
\text { económicas }\end{array}$ & 4,01 & $<.001^{*}$ & .268 & 0,80 & $>.250$ & .053 & 1,91 & $=.057$ & .128 & 7,00 & $<.001^{*}$ & .469 & 1,75 & $=.081$ & .117 & 4,67 & $<.001 * .313$ \\
\hline
\end{tabular}

* Comparaciones con diferencias significativas.

Fuente: Elaboración propia.

De manera accesoria, como puede verse en la Figura 2, el PIB de la República del Ecuador alcanza su máximo de los últimos 7 años precisamente en el 2014. Este pico del PIB no tiene ningún efecto en los homicidios, según los análisis realizados para los países estudiados; ni para su valor absoluto, $\mathrm{Tb}(56)=-.061$, $p=.511$, ni para el número de homicidios por cada 100,000 habitantes, $\operatorname{Tb}(56)=-.132, p=.155$. Como puede observarse en la Figura 3, el índice de desigualdad de la riqueza Gini tiene un repunte precisamente en el año 2014. Del mismo modo que con el PIB, tampoco existe correlación significativa, en los países internacionales mencionados anteriormente, entre este coeficiente de desigualdad de la riqueza y el número de homicidios; ni para su valor absoluto, $\mathrm{Tb}(22)=-.208, p=.176$, ni para su valor por cada 100,000 habitantes, $\operatorname{Tb}(22)=-.017, p=.91$.

Figura 2. Producto Interior Bruto de la República del Ecuador durante el periodo 2010-2016

$1,2 \mathrm{E}+11$

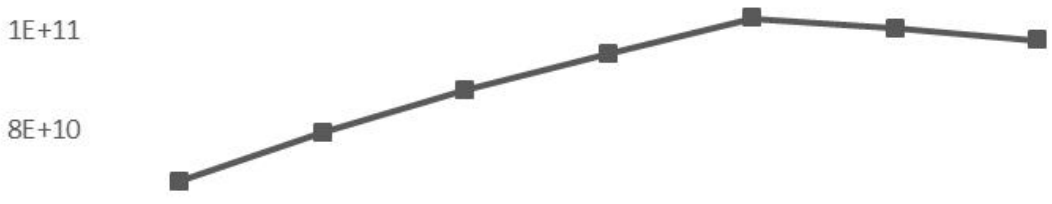

$6 \mathrm{E}+10$

$4 \mathrm{E}+10$

$2 \mathrm{E}+10$

0

$\begin{array}{lllllll}2010 & 2011 & 2012 & 2013 & 2014 & 2015 & 2016\end{array}$

Fuente: Elaboración propia. 
Figura 3. Índice Gini de desigualdad en el Reparto de la RiQueza para la República del Ecuador DURANTE EL PERIODO 2010-2016

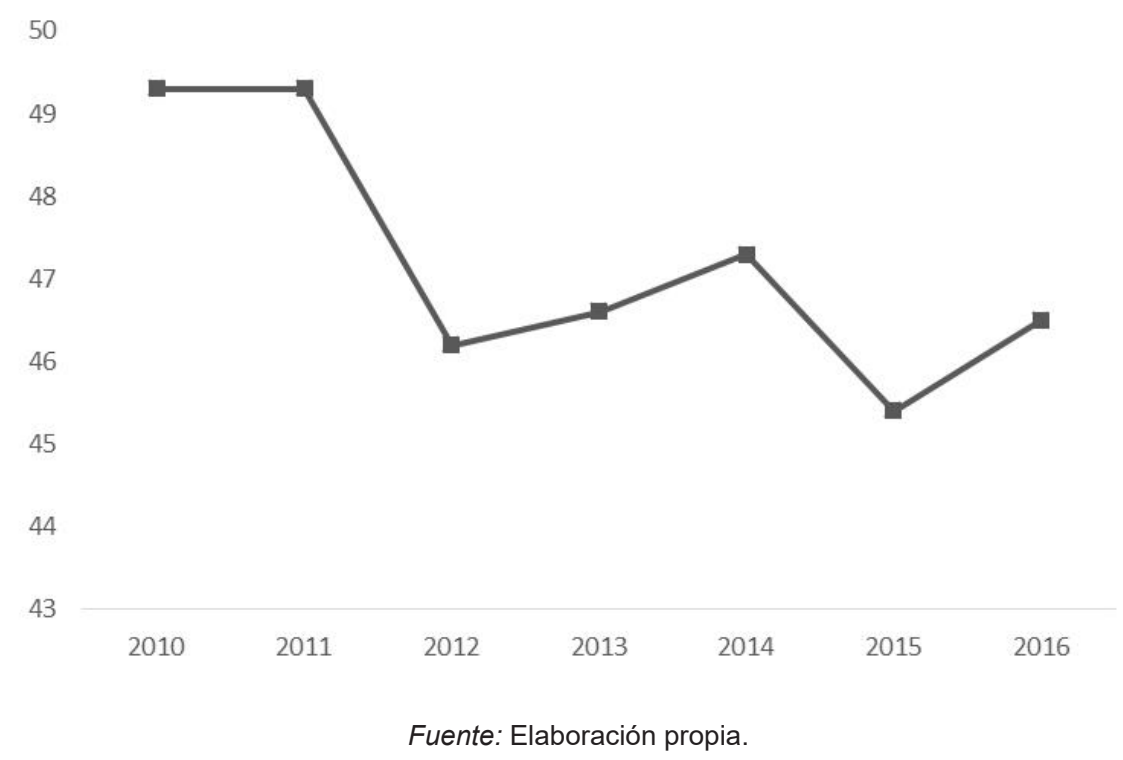

Según la Organización de las Naciones Unidas (ONU; $h$ ttp://www.un.org/en/member-states/index.html), existen 195 países reconocidos en el mundo. Los 46 países objeto del análisis de la correlación del PIB con los índices de criminalidad suponen un error muestral del $12.66 \%$ en su representatividad del universo total de países. Por otro lado, las 22 observaciones del análisis entre el coeficiente Gini y los índices de criminalidad suponen un $19.73 \%$ de error.

\subsection{Violaciones}

La evolución ascendente significativa, $X^{2}(6,222)=276.83, p<.001$, del promedio de violaciones inicia desde el año 2010 con un promedio de 11.79 ( $D E=54.08$ ) y finaliza en el 2016 con una media de 19.18 ( $D E$ $=58.43$ ) sucesos registrados en toda la República del Ecuador (ver Figura 4).

Figura 4. Media de violaciones Registradas en los 223 municipios de LA República del Ecuador DURANTE EL PERIODO 2010-2016

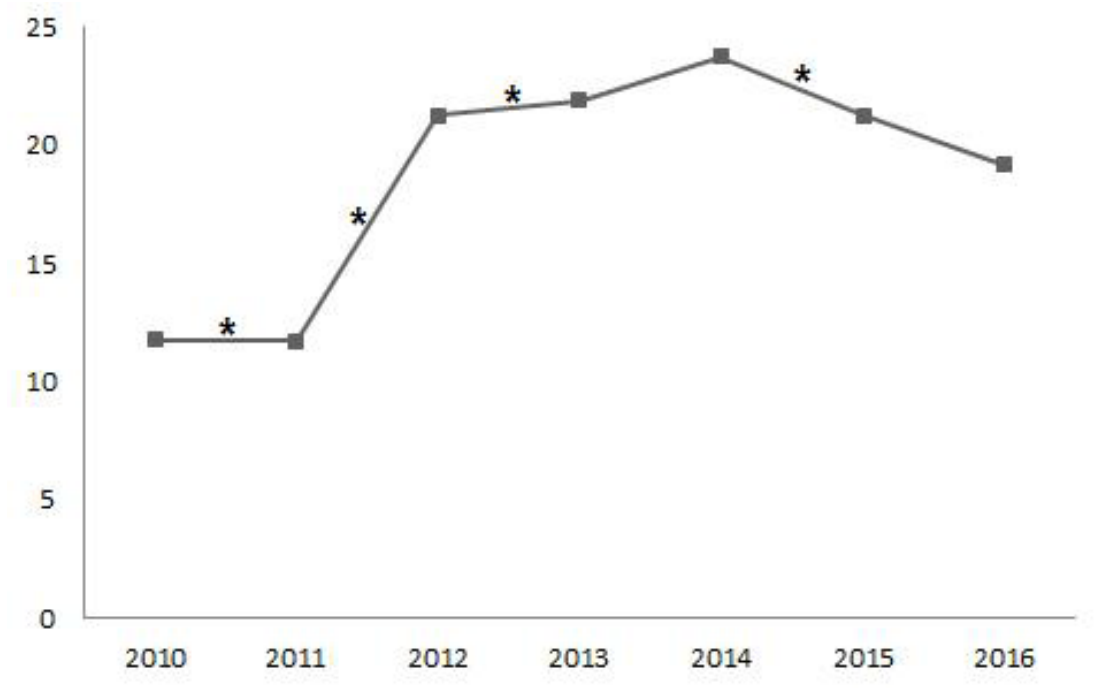

Fuente: Elaboración propia. 
La tendencia comienza con la disminución significativa de violaciones entre los años $2010(M=11.79$, $D E=54.08)$ y $2011(M=11.73, D E=33.59), Z(223)=3.03, p<.003, r=.203$ (ver Tabla 1 y Figura 2$)$. No obstante, entre los años $2011(M=11.73, D E=33.59)$ y $2012(M=21.27, D E=74.60)$ se registra un aumento significativo, $Z(223)=7.1, p<.001, r=.476$; tal como el registrado entre los años $2012(M=21.27$, $D E=74.60)$ y $2013(M=21.90, D E=73.04), Z(223)=1.99, p<.048, r=.133$. Los datos se estabilizan en el periodo 2013-2014; para posteriormente registrar un repunte descendente significativo entre el año 2014 ( $M$ $=23.74, D E=85.9)$ y el año $2015(M=21.23, D E=69.54), Z(223)=2.12, p<.035, r=.142$. Este descenso está influenciado por la mencionada actualización y reforma de la medida de límite de expendio de bebidas alcohólicas (Acuerdo Ministerial § 1470, 2014). Entre los años 2015 y 2016 no existen diferencias significativas aunque sigue existiendo una tendencia descendente.

El número de violaciones tampoco está influenciado por el PIB, ni en su valor absoluto, $\mathrm{Tb}(92)$ $=.023, p=.746$, ni en su valor por cada 100,000 habitantes, $\mathrm{Tb}(92)=-.059, p=.405$. De la misma manera, el índice de desigualdad Gini no parece estar afectando al número de sucesos en esta categoría, igualmente ni para su valor absoluto, $\mathrm{Tb}(18)=-.026, p=.879$, ni por cada 100,000 habitantes, $\mathrm{Tb}(18)$ $=.157, p=.363$.

\subsection{Robos en general}

Dentro de esta categoría de «robos en general», se tomará en cuenta todos los casos de robos, contando las seis subcategorías de registro siguientes: (a) robos a domicilios; (b) robos a personas; (c) robos de accesorios de vehículos; (d) robos de motos; (f) robos de vehículos; y (g) robos de unidades económicas. De forma general, los datos muestran un incremento de los robos desde el año 2010 hasta el año 2016 (ver Figura 5), $X^{2}(6,222)=565.39, p<.001$.

Figura 5. Media de robos en general Registrados en los 223 municipios de la República del Ecuador DURANTE EL PERIODO 2010-2016

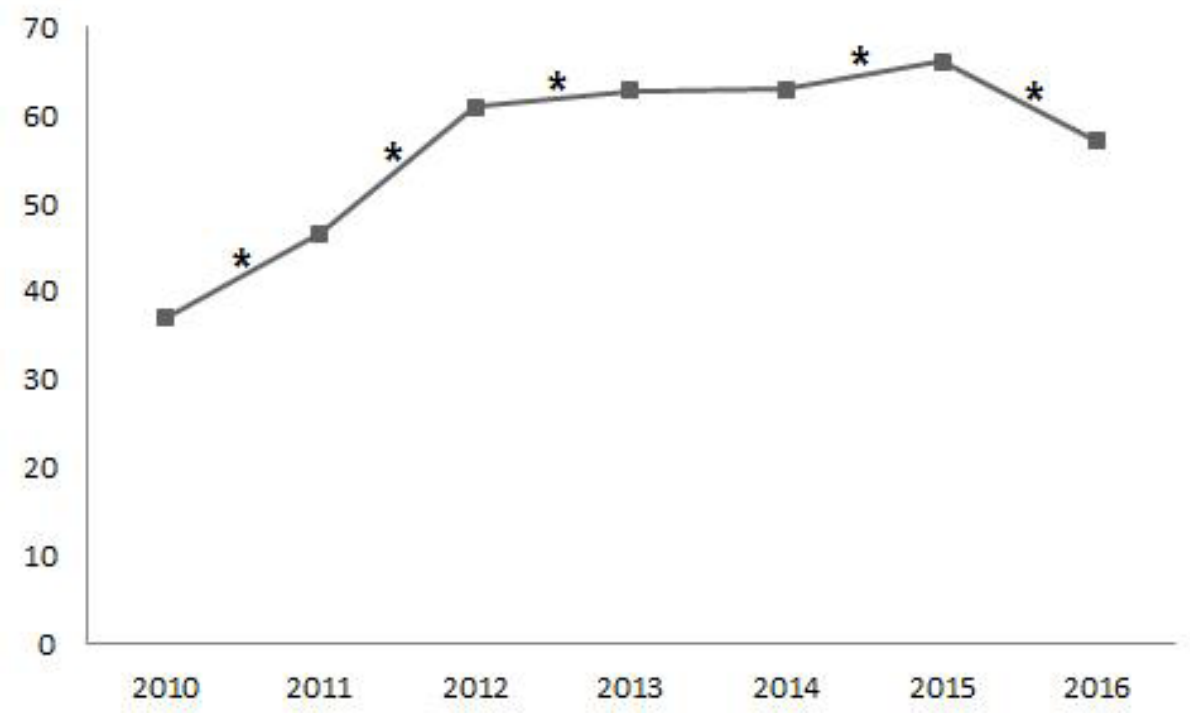

Fuente: Elaboración propia.

Analizando por años, existe un aumento significativo entre: (a) los años $2010(M=36.96, D E=225.79)$ y $2011(M=46.57, D E=306.27), Z(223)=10.06, p<.001, r=.673$; (b) $2011(M=46.57, D E=306.27)$ y 2012 $(M=60.98, D E=432.26), Z(223)=8.72, p<.001, r=.584$; y (c) $2012(M=60.98, D E=432.26)$ y $2013(M=$ 62.89, $D E=436.14$ ), $Z(223)=3.57, p<.001, r=.239$ (ver Tabla 1 y Figura 5). Por otro lado, existe: (a) una estabilización de los datos en el periodo 2013-2014; (b) un repunte ascendente significativo entre los años $2014(M=63.03, D E=420.38)$ y $2015(M=66.10, D E=456.11), Z(223)=2.42, p<.017, r=.162 ;$ y (c) un 
repunte descendente significativo entre los años $2015(M=66.10, D E=456.11)$ y $2016(M=57.08, D E=$ 396.13), $Z(223)=8.39, p<.001, r=.562$.

Según los datos registrados, los robos en general no se ven afectados ni por las medidas nacionales de control de armas (Acuerdo Ministerial $\S 2521,2009$ ) ni por el límite de expendio de bebidas alcohólicas; ni en su versión original (Acuerdo Ministerial § 1470, 2010) ni por su reforma (Acuerdo Ministerial § 1470, 2014). Sin embargo, los robos en general sigue un patrón similar al crecimiento y decrecimiento del PIB (ver figura 2 y 5). A tenor de los datos internacionales, sí hay una moderada relación significativa entre el PIB y el índice de robos por cada 100,000 habitantes, $\mathrm{Tb}(92)=.383, p<.001$. Igualmente, existe una correlación moderada significativa entre los índices de desigualdad de la riqueza y el número de robos en general tanto para su valor absoluto, $\mathrm{Tb}(19)=.357, p<.034$, como para su valor por cada 100,000 habitantes, $\mathrm{Tb}(19)=.509, p<.003$. Lo cual explicaría la estabilización de los datos en el 2014 (ver Figura 5), el repunte de aumento de robos en el 2015 (debido al incremento de la desigualdad en el 2014; ver Figura 3) y el repunte de decremento en 2016 (debido al decremento de la desigualdad para el 2015; ver Figura 3).

Robos a domicilios. En conjunto la evaluación muestra que los robos han ido en aumento significativo desde el año 2010 hasta el 2016 (ver Figura 6), $X^{2}(6,222)=243.75, p<.001$. Este aumento se debe a la relación significativa entre el PIB y el número de robos en general (ver Figura 2 y 5 ).

Figura 6. Media de Robos a domicilios Registrados en los 223 municipios de la República del EcuAdor DURANTE EL PERIODO 2010-2016

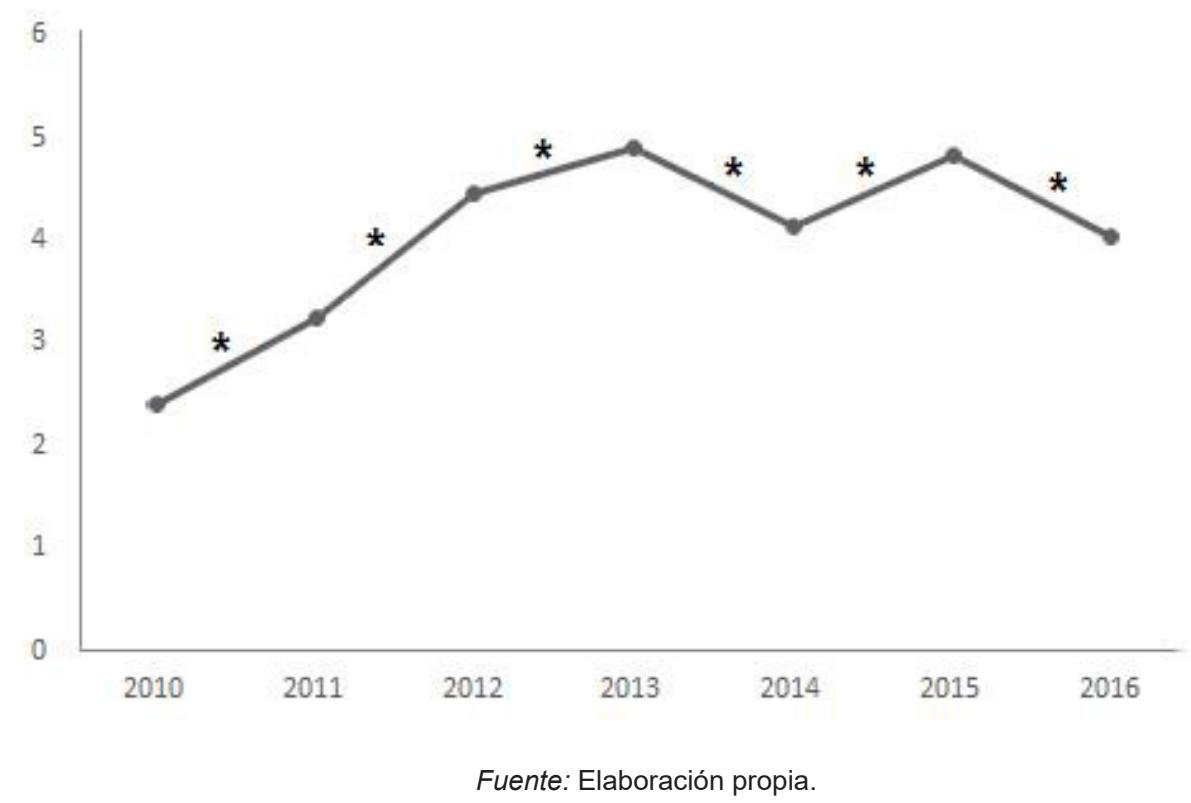

Al analizar por pareja de años, se puede evidenciar un incremento significativo entre los años: (a) 2010 $(M=55.03, D E=223.88)$ y $2011(M=66.4, D E=264.31), Z(223)=5.66, p<.001, r=.370 ;$ (b) $2011(M=66.4$, $D E=264.31)$ y $2012(M=85.65, D E=325.5), Z(223)=6.16, p<.001, r=.413 ; y$ (c) $2012(M=85.65, D E=$ $325.5)$ y $2013(M=89.78, D E=297.01), Z(223)=2.9, p<.005, r=.194$. Entre los años $2013(M=89.78, D E$ $=297.01)$ y $2014(M=79.4, D E=291.49)$ existe un descenso significativo, $Z(223)=5.94, p<.001, r=.398$; motivado por la reforma de la medida del límite de expendio de medida alcohólicas (Acuerdo Ministerial $\S$ $1470,2014)$. Por el contrario, entre los años $2014(M=79.4, D E=291.49)$ y $2015(M=86.32, D E=315.1)$ se produce un aumento significativo, $Z(223)=4.65, p<.001, r=.311$, y entre los años $2015(M=86.32$, $D E$ $=315.1)$ y $2016(M=72.32, D E=260.95)$ se produce de nuevo un descenso significativo, $Z(223)=5.83, p$ $<.001, r=.39$.

Robos a personas. El patrón de robos a personas es muy similar al del robo a domicilios (ver Figura 6 y 7). Igualmente, existe un aumento significativo desde el año 2010 hasta el $2015, X^{2}(6,222)=82.98, p<.001$. De la misma forma que en el apartado anterior, los datos deben su patrón a la relación significativa del PIB y el número de robos en general (ver Figura 2 y 5 ). 
Figura 7. Media de Robos a PERsonas Registrados en los 223 municipios de LA RepúblicA del ECUAdor DURANTE EL PERIODO 2010-2016

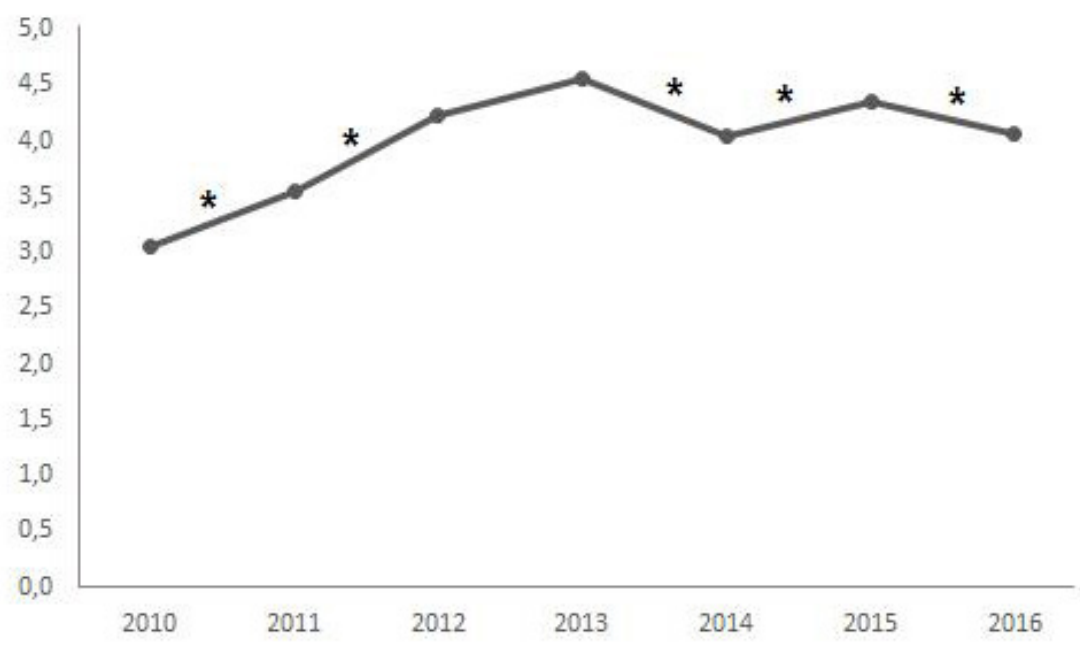

Fuente: Elaboración propia.

Al analizar por pareja de años consecutivos, se evidencia un aumento significativo entre los años: (a) $2010(M=77.86, D E=435.51)$ y $2011(M=106.24, D E=622.36), Z(223)=5.13, p<.001, r=.344$; y (b) 2011 $(M=106.24, D E=622.36)$ y $2012(M=153.7, D E=935.05), Z(223)=4.16, p<.001, r=.279$. Entre el año 2013-2014, se estabilizan los datos. Por otro lado: (a) entre los años $2013(M=158.56, D E=953.5)$ y 2014 $(M=143.2, D E=848.77)$ se evidencia un descenso significativo, $Z(223)=3.14, p<.002, r=.228$; (b) entre los años $2014(M=143.2, D E=848.77)$ y $2015(M=154.39, D E=936.23)$ se produce un aumento significativo, $Z(223)=2.29, p<.023, r=.154 ; \mathrm{y}(\mathrm{c})$ entre los años $2015(M=154.39, D E=936.23)$ y $2016(M=133.29$, $D E=815.83$ ) se produce de nuevo un descenso significativo, $Z(223)=2.59, p<.011, r=.173$. El descenso entre los años 2013-2014 vuele a deberse a la reforma y actualización de la medida de límite de expendio de bebidas alcohólicas (Acuerdo Ministerial § 1470, 2014).

Robos de accesorios a vehículos. El patrón de robos de accesorios de vehículos aumenta desde el año 2010 hasta el 2015 (ver Figura 8 ), $X^{2}(6,222)=249.38, p<.001$. El aumento general vuelve a deberse a la relación significativa entre robos y PIB.

Figura 8. MEdia de Robos de ACCESORIOS DE VEHículos REGISTRAdOS EN LOS 223 MUNICIPIOS DE LA REPÚblicA DEL ECUAdOR DURANTE EL PERIOdO 2010-2016

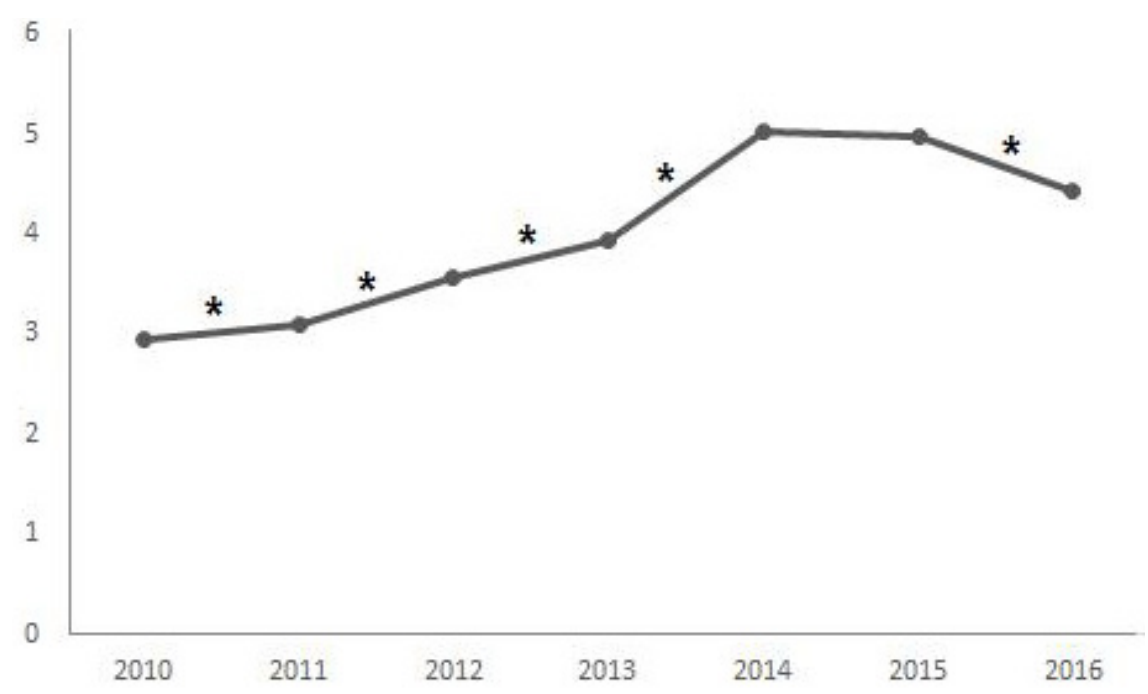

Fuente: Elaboración propia. 
Desde el año $2010(M=17.78, D E=113.97)$ y $2011(M=29.16, D E=213.14), Z(223)=2.92, p<.005, r$ $=.195$, hasta el año entre el $2013(M=45.58, D E=288.28)$ y $2014(M=65.4, D E=428.85)$ se evidencia un ascenso significativo, $Z(223)=7.11, p<.001, r=.576$. En el periodo 2014-2015 los datos se estabilizan para en el periodo de entre los años $2015(M=65.84, D E=440.8)$ y $2016(M=52.41, D E=358.88)$ producirse de nuevo un descenso significativo, $Z(223)=5.13, p<.001, r=.343$. Ninguna de las medidas nacionales parece estar detrás de este patrón de resultados.

Robos de motocicletas. Los robos de motocicletas han experimentado un aumento significativo desde el 2010 al 2016 (ver Figura 9), $X^{2}(6,222)=31.44, p<.001$ (ver Figura 9). El aumento total en esta área vuelve a deberse a la relación significativa entre el número de robos y el PIB; siguiendo un patrón similar al del PIB (ver Figura 2).

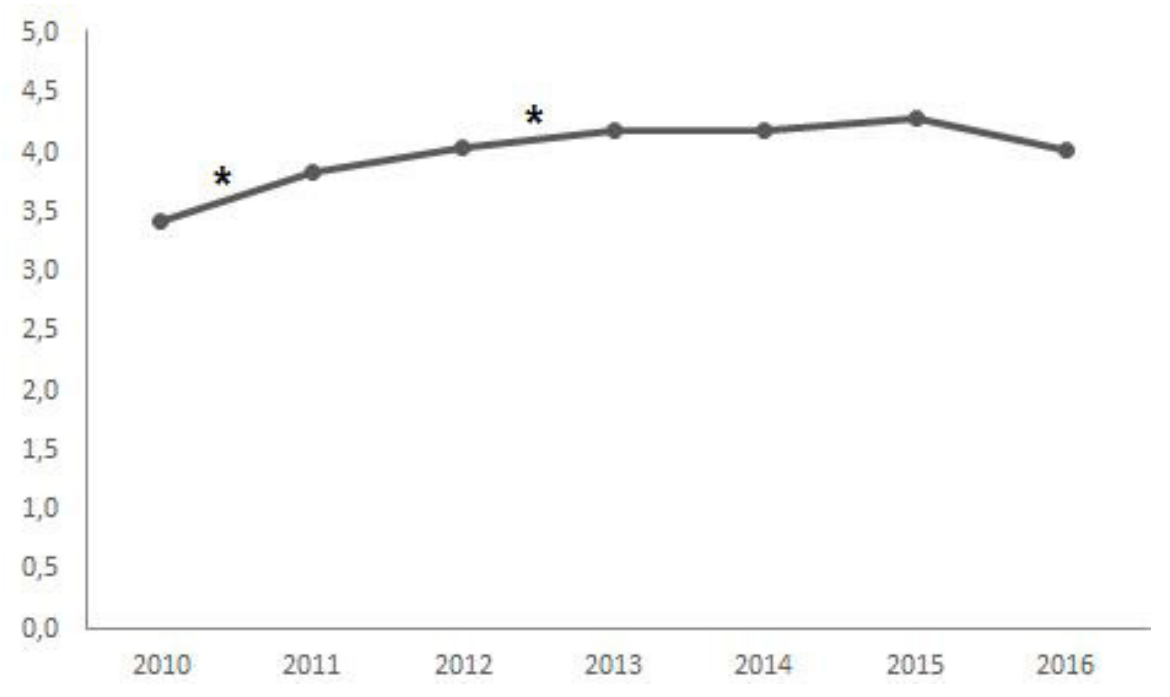

FIGURA 9. MEdiA de RoBos A MOTOS REGISTRADOS EN LOS 223 MUNICIPIOS DE LA REPÚBLICA DEL ECUADOR DURANTE EL PERIODO 2010-2016

Durante dos periodos este aumento se ha incrementado de forma significativa: (a) periodo entre el 2010 $(M=22.43, D E=88.17)$ y $2011(M=25.12, D E=89.58), Z(223)=4.09, p<.001, r=.274 ; \mathrm{y}$ (b) periodo entre el $2012(M=24.39, D E=80.38)$ y $2013(M=27.65, D E=95.4), Z(223)=2.22, p<.027, r=.149$. Ninguna de las medidas nacionales parece estar detrás de este patrón de resultados.

Robos de vehículos. Los robos de vehículos experimentaron una fluctuación significativa desde el 2010 hasta el 2016, $X^{2}(6,222)=120.52, p<.001$ (ver Figura 10). Este aumento y disminución sigue un patrón similar al del PIB (ver Figura 2).

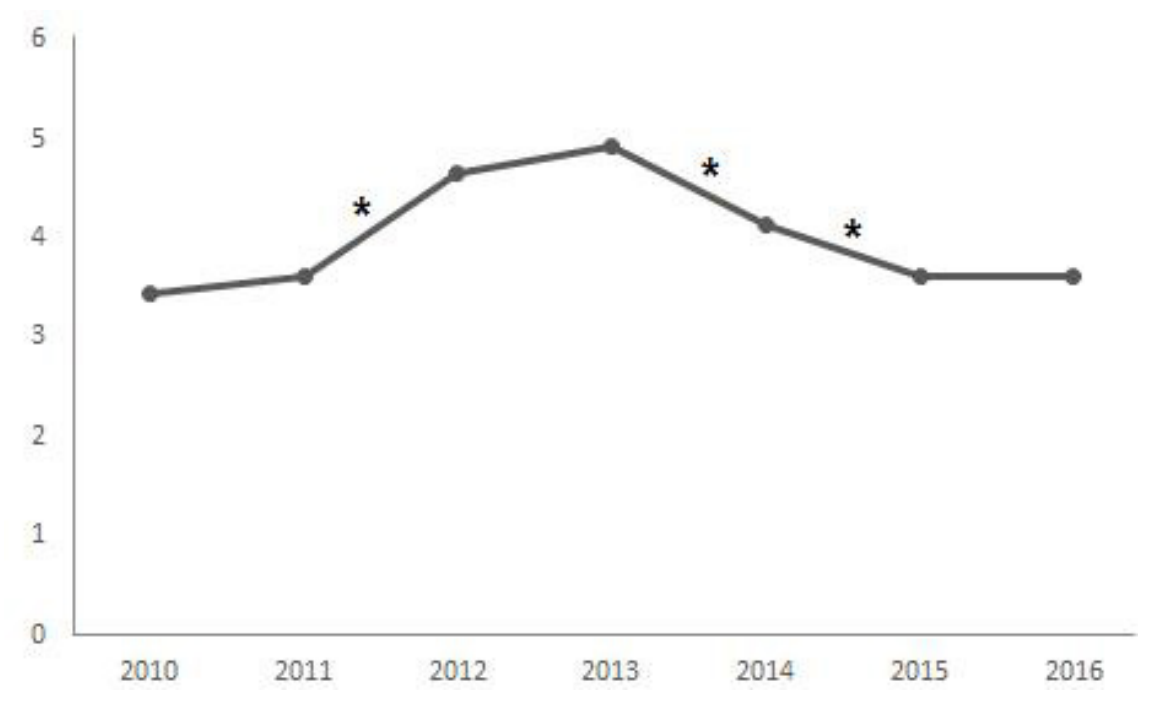

Figura 10. Media de Robos A VEHÍCULOS REGISTRADOS EN LOS 223 MUNICIPIOS DE LA RePÚBLICA DEL ECUADOR DURANTE EL PERIODO 2010-2016 
Del $2011(M=28.94, D E=195.47)$ al $2012(M=35.56, D E=209.98), Z(223)=5.26, p<.001, r=.353$, existió un incremento significativo. Hubo un decremento significativo en los periodos del $2013(M=33.65, D E$ $=181.92)$ al $2014(M=28.97, D E=175.36), Z(223)=5.56, p<.001, r=.372$, y en el periodo del $2014(M=$ 28.97, $D E=175.36)$ al $2015(M=22.1, D E=139.97), Z(223)=3.73, p<.001, r=.25$. Ninguna de las medidas nacionales parece estar detrás de este patrón de resultados.

Robos de unidades económicas. Al igual que en patrones de resultados anteriores, existe una fluctuación creciente desde el 2010 al 2016, $X^{2}(6,222)=169.93, p<.001$ (ver Figura 11). Esta fluctuación creciente vuelve a deberse a la relación significativa entre robos y PIB.

Figura 11. Media de Robos de unidades eConómicas Registrados en los 223 municipios de LA República DEL ECUADOR DURANTE EL PERIODO 2010-2016

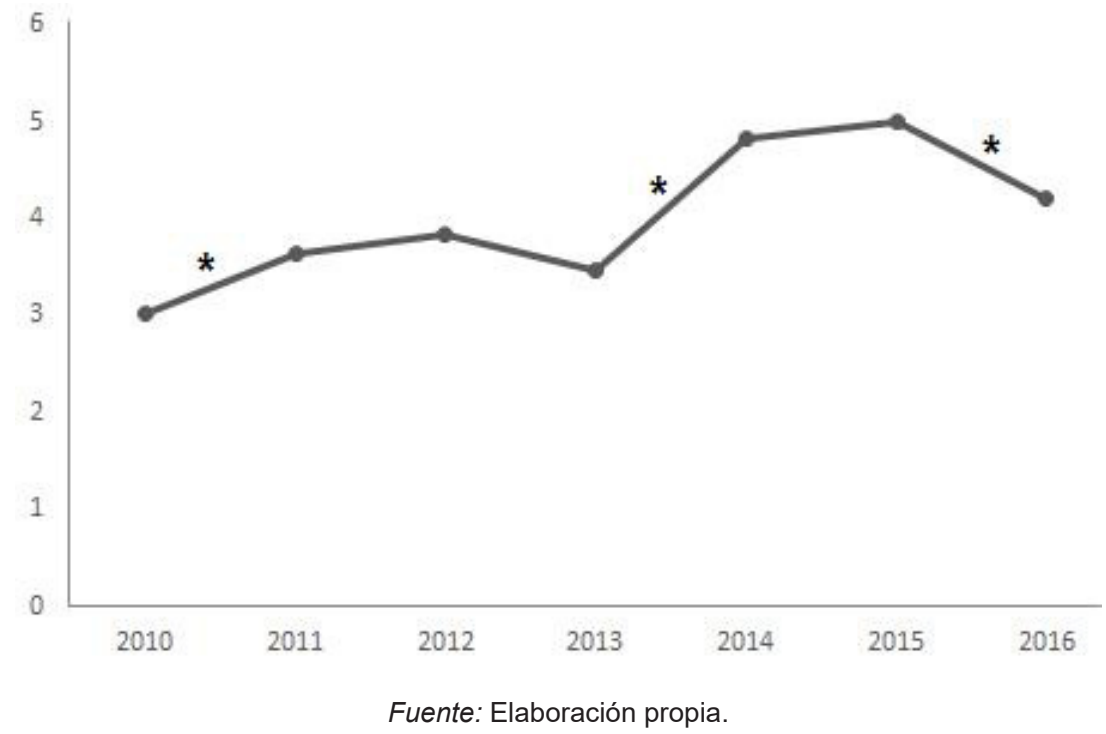

Existe un incremento inicial significativo del número de robos de unidades económicas durante el periodo entre el $2010(M=22.97, D E=91.19)$ y $2011(M=23.53, D E=102.39), Z(223)=4.01, p<.001, r=.268$. Al contrario que en tendencias anteriores, durante el periodo entre el $2013(M=22.09, D E=92.41)$ y 2014 $(M=32.05, D E=155.85)$, el número de robos de unidades económicas se incrementó significativamente, $Z(223)=7, p<.001, r=.469$. Este aumento parece estar debido al repunte de aumento de desigualdad en el Ecuador medido con el índice Gini (ver Figura 3). Existe un significativo descenso de este índice durante el último periodo entre los años $2015(M=33.99, D E=166.66)$ y $2016(M=26.61, D E=129.37), Z(223)=$ $4.67, p<.001, r=.313$.

\section{CONCLUSIONES}

Según los datos analizados, las medidas políticas de ámbito nacional en la República del Ecuador han tenido un efecto significativo sobre ciertos índices de criminalidad. En la influencia sobre ciertos, se debe tener en cuenta factores económicos, dado que el PIB y el índice Gini tienen una relación significativa positiva con los índices de robos en general. No obstante, para este índice, las medidas de expendio de bebidas alcohólicas (tanto en su versión inicial como en su reforma) han aportado las circunstancias necesarias para ayudar a que dichos índices decrezcan (compensando a los factores económicos).

EI PIB de la República del ecuador aumentó desde el 2010 al 2014. Parce ser que cuanto más dinero hay en un país (PIB) y peor está distribuido (índice Gini), más robos se comenten; al menos a tenor de los países analizados en nuestro estudio (con el índice de error muestral estipulado). Es particularmente llamativo el caso de los robos a domicilios, personas y vehículos en el Ecuador. Mientras el PIB y el índice Gini aumentan para el año 2014, la medida de regulación el expendio de bebidas alcohólicas es reformada y aplicada ese mismo año, lo cual hace que los índices de robos en las categorías menciona- 
das (no para las categorías de robos en general) decrezca significativamente. La explicación la podemos encontrar en la literatura. La criminalidad ha sido relacionada con la nocturnidad (e.g., Bolaños-Briceño y Ariza-Marin, 2017; Borgognoni, 2014). Es lógico y evidente que, si una medida provoca que la gente no tenga ningún motivo para estar en la calle (ya que los locales de recreación cierran a las dos de la mañana), los delincuentes destaquen más en unas condiciones en las que, al no haber más gente, se les pueda identificar mejor.

En el caso de los homicidios y de las violaciones, no existe relación significativa entre el PIB y el índice Gini, lo cual sólo deja a las medidas políticas como posibles causas de los descensos experimentados. En primer lugar, la tendencia en homicidios es totalmente descendente desde el año 2010, un año después de la implantación de la medida regulatoria de armas de fuego. Es de sentido común, pero se necesitan datos que lo respalden, que, al no tener armas de fuegos tan disponibles, las rencillas sean menos probables de saldarse con muertos. Este descenso se ve respaldado tanto por la medida del 2010 (como por su reforma del 2014) del límite de expendio de bebidas alcohólicas.

En el caso de las violaciones, sólo parecen estar influenciadas por las medidas de expendio de alcohol. Como se ha detallado antes, existe en la literatura una relación entre la criminalidad y nocturnidad. En este caso, es igualmente lógico y evidente que el hecho de que los locales de recreación estén cerrados provoca que los ciudadanos no estén en la calle a altas horas de la madrugada. Los ciudadanos (independientemente de su sexo) no se exponen a ir solos tanto para su ida como su regreso a casa y, con ello, no se dan las condiciones de nocturnidad que protegen a la criminalidad.

Tenemos que ser críticos con nuestro estudio. Es impepinable que existe innumerables factores que afectan a los índices de criminalidad y que se escapan tanto a la administración política como al presente estudio. Lo que sí se puede afirmar es que las medidas políticas, al menos, no han sido contraproducentes. Quizá, el ejemplo más claro es el del número de homicidios. No siendo objeto de influencia económica (ni del PIB ni del índice de desigualdad Gini) el hecho de que no cualquier ciudadano pueda disponer de armas de fuego ha hecho que los homicidios en la República del Ecuador hayan disminuido significativa y sensiblemente desde el 2010.

Como comenzada este trabajo, la eficacia percibida de un sistema político debería orientar las actitudes y conductas de participación política. En este sentido, centrándonos en los datos, el gobierno que instauró estas medidas fue eficiente a la hora de servir a la ciudadanía (como debería ser el objetivo de todo gobierno). Si bien es cierto que en este área, este gobierno tomó decisiones acertadas (al menos, no contraproducentes) también hay que tener en cuenta que existen innumerables ámbitos de acción política y que todos deberían evaluarse con la misma visión crítica.

Las medidas políticas provienen de los agentes decisores, ya sean administrativos o políticos. La eficacia de dichas medidas ha de ser evaluada y debe servir de criterio para la renovación, cesión o instrucción de cargos públicos. El ciudadano deber ser un supervisor del sistema político para proporcionar el espacio necesario para su mejora. Se requiere de la implantación estándar de sistemas de registro y análisis de la gestión pública para una mejor educación y compromiso del ciudadano que no sólo debe restringirse a ir a votar sino que debe convertirse en un verdadero supervisor del sistema. Sólo de esta manera puede realizarse retroalimentación de la función pública en todos sus aspectos y, de este modo, provocar el continuo mejoramiento de las capacidades, decisiones y planteamientos del servidor público.

\section{REFERENCIAS BIBLIOGRÁFICAS}

ABASCAL, W.; ESTEVES, E.; GOJA, B., GONZÁLEZ, F.; LORENZO, A.; SICA, A. (2013): "Impacto de las políticas de control de tabaco en el Uruguay. 2006-2009: Programa Nacional para Control del Tabaco", en Archivos de Medicina Interna, vol. 35, núm. 4, págs. 1-16. URL: http://www.scielo.edu.uy/scielo.php?script=sci_ arttext\&pid=S1688-423X2013000400001\&Ing=es\&tIng=es.

AGUILERA C. I. (2000): "Un enfoque gerencial de la teoría de las restricciones", en Estudios Gerenciales, vol. 16, núm. 77, págs. 53-69. URL: http://www.scielo.org.co/scielo.php?script=sci_arttext\&pid=S0123-59232000000400004.

AGUIRRE BRIONES, A. (2009): "Política social e indicadores distributivos: Elementos para una caracterización de la política social en Chile”, en Polis, vol. 8, núm. 22, págs. 231-248. URL: https://scielo.conicyt.cl/scielo. php?script=sci_arttext\&pid=S0718-65682009000100014\&/ng=es\&nrm=iso\&tlng=es.

BANCO MUNDIAL (2017a): Índice de Gini. URL: https://datos.bancomundial.org/indicador/SI.POV.GINI?view=map.

BANCO MUNDIAL (2017b): PIB (US\$ a precios actuales). URL: https://datos.bancomundial.org/indicador/NY.GDP. MKTP.CD?view=chart. 
GAPP. Nueva Época - N. 23, mayo-octubre 2020 - ISSN: 1989-8991 - DOI: 10.24965/gapp.i23.10754 - [Págs. 152-166]

Eficacia de las medidas políticas e índices internacionales de criminalidad: el caso de la República del Ecuador Jose Luis Vilchez Tornero / Román Mauricio Buñay Andrade

BEDOYA BEDOYA, M. R. (2015): "El papel de las políticas públicas de migración y retorno en Colombia en el marco de la crisis económica mundial: los casos del Eje Cafetero, Cali, Medellín y Bogotá”, en Estudios Políticos, núm. 46, págs. 79-99. URL: https://aprendeenlinea.udea.edu.co/revistas/index.php/estudiospoliticos/article/view/18770.

BLANCO BOSCO, E. (2009): "Eficacia escolar y desigualdad: aportes para la política Educativa", en Perfiles Latinoamericanos: Revista de la Facultad Latinoamericana de Ciencias Sociales (FLACSO), vol. 17, núm. 34, págs. 31-85. URL: https://perfilesla.flacso.edu.mx/index.php/perfilesla/article/view/159.

BOLAÑO-BRICEÑO, J. A.; ARIZA-MARIN, L. J. (2017): "Nocturnidad, ciudades 24 horas y sus efectos socioambientales", en Bitácora Urbano Territorial, vol. 27, núm. 3, págs. 127-132. DOI: https://doi.org/10.15446/ bitacora.v27n3.66450.

BORGOGNONI, E. (2014): "El tiempo del delito en las ciudades castellanas a fines de la Edad Media", en En la España Medieval, vol. 37, págs. 223-246. DOI: https://doi.org/10.5209/rev ELEM.2014.v37.44456.

DAVIS, J. H.; STASSON, M.; ONO, K.; ZIMMERMAN, S. (1988): "Effects of straw polls on group decision making: Sequential voting pattern, timing and local majorities", en Journal of Personality and Social Psychology, vol. 55, núm. 9, págs. 18-926. DOI: https://doi.org/10.1037/0022-3514.55.6.918.

DÍAZ POLANCO, J.; CANDELA, Y. (2014): "Políticas alimentarias y nutricionales en los sistemas nacionales de salud", en Anales Venezolanos de Nutrición, vol. 27, núm. 1, págs. 143-152. URL: https://www.analesdenutricion. org.ve/ediciones/2014/1/art-19/.

DION, K. L.; BARON, R. S.; MILLER, N. (1970): "Why do groups make riskier decisions than individuals?", en Advances in Experimental Social Psychology, vol. 5, págs. 305-377. DOI: https://doi.org/10.1016/S00652601(08)60094-5.

FARR, R.; MOSCOVICI, S. (eds.): Social representations. Cambridge: Cambridge University Press.

GALAM, S.; MOSCOVICI, S. (1991): "Toward a theory of collective phenomena: Consensus and attitude changes in group", en European Journal of Social Psychology, vol. 21, núm. 1, págs. 49-74. DOI: https://doi.org/10.1002/ ejsp.2420210105.

MYERS, D. G.; BISHOP, G. D. (1970): "Discussion effects on racial attitudes”, en Science, vol. 169, núm. 3.947, págs. 778-779. DOI: https://doi.org/10.1126/science.169.3947.778.

MOSCOVICI, S. (1984): "The phenomenon of social representations", en FARR, R.; MOSCOVICI, S. (eds.): Social representations, págs. 3-69. Cambridge: Cambridge University Press.

MOSCOVICI, S.; ZAVALLONI, M. (1969): "The group as a polarizer of attitudes", en Journal of Personality and Social Psychology, vol. 12, núm. 2, págs. 125-135. DOI: https://doi.org/10.1037/h0027568.

REPÚBLICA DEL ECUADOR (2009): Instructivo para la Intervención de los Intendentes Generales de la Policía del país. Acuerdo Ministerial § 2521. Registro Oficial Suplemento núm. 729, de 21 de junio del 2012. Quito: Ministerio del Interior. URL: https://www.derechoecuador.com/registro-oficial/2012/06/registro-oficial-no-729--jueves-21-dejunio-del-2012-suplemento.

REPÚBLICA DEL ECUADOR (2014): Reforma a la regulación de venta de bebidas alcohólicas. Acuerdo Ministerial $\S$ 1470. Registro Oficial Suplemento 287, de 11 de julio de 2014. Quito: Ministerio de Turismo, Gobierno de la República del Ecuador. URL: https://www.turismo.gob.ec/wp-content/uploads/2016/04/ACUERDO-1470EXPENDIO-DE-BEBIDAS-ALCOHOLICAS-EN-ESTABLECIMIENTOS-TURISTICOS-Y-NO-TURISTICOS.pdf.

REPÚBLICA DEL ECUADOR (2010): Regulación de venta de bebidas alcohólicas. Acuerdo Ministerial § 1470. Registro Oficial núm. 233, de 12 de julio del 2010. Quito: Ministerio de Turismo, Ministerio de Gobierno, Policía y Cultos. URL: https://www.derechoecuador.com/registro-oficial/2010/07/registro-oficial-no-233---lunes-12-de-juliode-2010.

LAM DÍAZ, R. M.; HERNÁNDEZ RAMÍREZ, P. (2008): "Los términos: eficiencia, eficacia y efectividad ¿son sinónimos en el área de la salud?", en Revista Cubana de Hematología, Inmunología y Hemoterapia, vol. 24, núm. 2. URL: http://scielo.s/d.cu/scielo.php?script=sci_arttext\&pid=S0864-02892008000200009\&/ng=en\&nrm=iso\&t/ng=es.

OFICINA DE LAS NACIONES UNIDAS CONTRA LA DROGA Y LOS CRÍMENES (UNODC) (2015): Clasificación Internacional de Delitos con Fines Estadísticos. URL: https://www.unodc.org/documents/data-and-analysis/ statistics/crime/ICCS/ICCS_SPANISH_2016_web.pdf.

PASTOR SELLER, E. (2012): "Sostenibilidad, impacto y eficacia de las Políticas Sociales municipales mediante la democratización e implicación social", en Sociedade e Estado, vol. 27, núm. 3, págs. 663-688. URL: https:// periodicos.unb.br/index.php/sociedade/article/view/5688. DOI: https://doi.org/10.1590/s0102-69922012000300012.

RIVERA, R.; CASTILLO, G.; ASTETE, M.; LINARES, V.; HUANCO, D. (2005): "Eficacia de un programa de capacitación en medidas básicas de prevención de infecciones Intrahospitalarias", en Revista Peruana de Medicina Experimental y Salud Publica, vol. 22, núm. 2, págs. 88-95. URL: https://rpmesp.ins.gob.pe/index.php/ rpmesp/article/view/1013. DOI: https://doi.org/10.17843/rpmesp.2005.222.1013.

RODRÍGUEZ-PONCE, E. R. (2007): "Gestión del conocimiento y eficacia de las organizaciones: un estudio empírico en instituciones públicas”, en Interciencia: Revista de ciencia y tecnología de América, vol. 32, núm. 12, págs. 820826. URL: http://ve.scielo.org/scielo.php?script=sci_arttext\&pid=S0378-18442007001200006.

SANDÍN-VÁZQUEZ, M.; SARRÍA-SANTAMERA, A. (2008): "Evaluación de impacto en salud: valorando la efectividad de las políticas en la salud de las poblaciones", en Revista Española de Salud Pública, vol. 82, núm. 3, págs. 261272. URL: $h$ ttp://scielo.isciii.es/pdf/resp/v82n3/colaboracion2.pdf. 
STONER, J. A. F. (1961): A comparison of individual and group decisions involving risk, Master Thesis. Massachusetts: Massachusetts Institute of Technology (MIT), School of Industrial Management. URL: http://hdl.handle. net/1721.1/11330.

VALDIVIA, C.; RIVADENEIRA, L.; ZUMÁRRAGA, M. (2010): Evolución de las variables investigadas en los censos de población y vivienda del Ecuador: 1950, 1962, 1974, 1982, 1990, 2001 y 2010 . Quito, Ecuador: Instituto Nacional de Estadísticas y Censos (INEC). URL: https://www.ecuadorencifras.gob.ec//documentos/web-inec/ Publicaciones/Evolucion_variables_1950_2010_24_04_2014.pdf.

VILCHEZ, J. L. (2016): "Mental footnotes: Knowledge constructivism from logical thinking to personal beliefs and therapy", en Research in Psychotherapy: Psychopathology, Process and Outcome, vol. 19, núm. 2, págs. $157-164$. DOI: $h$ ttps://doi.org/10.4081/ripppo.2016.234.

YOPO DÍAZ, M. (2012): "Políticas sociales y pueblos indígenas en Chile: Aproximación crítica desde la noción de agencia”, en Universum. Revista de Humanidades y Ciencias Sociales, vol. 27, núm. 2, págs. 187-208. DOI: https://doi.org/10.4067/s0718-23762012000200011. 